

\title{
Editorial
}

\section{London swoops on Australian paramedics}

\author{
Jaime Wallis BEH, GradCertHPE, ${ }^{1}$ Linda Ross MHlthProfEd, ${ }^{1}$ Malcolm Boyle PhD ${ }^{1}$
}

\author{
Affiliation: \\ ${ }^{1}$ Monash University, Victoria
}

It was the online commentary around this time last year titled 'London's calling our paramedics' by Karen Keast that raised interest in different sections of Australia (1). The article discussed the growing demand on the London Ambulance Service NHS Trust (LAS) and the need for the service to look overseas for qualified or newly graduated paramedics. Ambulance demand is an aspect that we can relate to here in Australia but the shortage of newly graduated paramedics is not an issue in Australia. Anecdotally, paramedic degrees have been extremely popular and numbers of new ambulance paramedic graduates in Australia has increased disproportionately to the jobs available. So why has this lack of paramedic graduates occurred in the United Kingdom (UK)? Ultimately it came down to professional registration and the commitment that LAS has made to have more registered healthcare professionals overseeing patient care in the UK. Support from the government saw the LAS granted permission to sponsor work visas for non-European paramedics.

The past year has played witness to LAS conducting an extensive recruiting campaign in Australia for the first time. The similarities in training, competencies and skills of the Australia and UK paramedics, has best placed Australian paramedics to fill this shortage. Not only was the campaign extensive it was also innovative. LAS recruitment personnel approached tertiary education providers and attended national conferences in an effort to lure paramedics and graduate paramedics to the UK. Was it successful? Well, 175 Australian paramedics joining the LAS in the recent months would suggest so (2).

Those who applied progressed through an extensive assessment process including written and oral clinical examinations, a cardiac arrest scenario and behavioural interview. In addition to the employment with LAS, recruits receive financial support to relocate to London, and are required to undergo a short conversion course prior to being deployed.

A large majority of these new recruits comprise newly graduated paramedics, many of whom view this unique and exciting opportunity to begin their paramedic careers internationally as exhilarating. The attraction to work in London was apparent when LAS interviewed a recent graduate, Mitchell Hand, from Sydney "I'm looking forward to being out there in the hustle and bustle of London among the iconic buildings that l've only ever seen on the Monopoly board before" (2).

The first consignment of newly trained LAS ambulance paramedics hit the road just in time to celebrate Australia Day in the UK and the recruitment campaign has not stopped. The next round of applications are being compiled for a March intake and the rumour mill is circulating that an estimated 400 positions still remain unfilled.

In the paramedic profession it is opportunities like these that not only provide a solid foundation for any clinician in pre-hospital care and management; it also provides a fantastic opportunity for newly graduated paramedics to experience the London lifestyle and live abroad.

So it is true. London is calling our paramedics and our paramedics are hearing them loud and clear. What this means for the regional ambulance services here in Australia...I guess we'll see in the coming months and years.

More information about how to apply to work for the London Ambulance Service can be found at www.noordinarychallenge.com/.

In this issue of the Australasian Journal of Paramedicine (AJP) is the study by McGarry and colleagues investigates the inclusion of mental health consumers and carers input into lectures for the paramedic and nursing mental health subjects at Charles Sturt University (3). The study by Burnett and colleagues from the United States of America provides some important findings when comparing Ketamine and other drugs for chemical restraint in managing agitated patients (4). The article 'Pathway to Paramedicine Perspectives' by Ross and Bertucci is part 2 of a study looking at the paramedic student views of the program (5), part one of the study which looked at the secondary school student views was published in the November 2014 issue of AJP (6). 
The study by Reed and Bendall looks at ambulance use by rural people in New South Wales and finds like other studies there is a disparity between rural and city use, an issue relevant to all of Australia and most other jurisdictions internationally (7).

Jaime Wallis, Linda Ross and Dr Malcolm Boyle

Monash University, Victoria

\section{References}

1. Keast K. London's calling our paramedics. Nursing Careers Allied Health 2015. Available at: www.ncah.com.au/news-events/ londons-calling-our-paramedics/2011/ [Accessed 5 December 2014].

2. London Ambulance Service. Australia Day marks first shift on the road for paramedics from Down Under. London Ambulance Service NHS Trust2015 Available at: www.londonambulance.nhs.uk/news/news_releases_and_statements/australia_day_ marks_first_shif.aspx [Accessed 26 January 2015].

3. McGarry D, Andrews N, Buchta M, Kent K, McFarlane C, McFarlane J. Capturing the Experience: Lessons of Consumers and Carers in Rural Mental Health Education. Australasian Journal of Paramedicine 2015;12(1).

4. Burnett A, Panchal D, Peterson B, et al. The Administration of Prehospital Ketamine for Chemical Restraint does not Prolong On-Scene Times Compared to Haloperidol Based Sedation. Australasian Journal of Paramedicine 2015;12(1).

5. Ross L, Bertucci J. Pathway to Paramedicine Program perspectives - Part 2 secondary school students. Australasian Journal of Paramedicine 2015;12(1).

6. Ross L, Bertucci J. Pathway to Paramedicine Program perspectives - Part 1 Paramedic Students. Australasian Journal of Paramedicine 2014;11(6).

7. Reed B, Bendall J. Rural people's use of ambulances to reach emergency departments in potentially serious health emergencies: Identifying patterns of use and non-use. Australasian Journal of Paramedicine 2015;12(1). 